\title{
Laura Alba-Juez / Lachlan Mackenzie, Pragmatics: cognition, context and culture, McGraw Hill / UNED, 2016, 324 pp. ISBN: 978-84-486-o76o-9.
}

Entender la pragmática es imprescindible para la comprensión del funcionamiento del lenguaje humano y de sus múltiples facetas. La riqueza de la pragmática reside en que no solo tiene en consideración los datos estrictamente lingüísticos (textos escritos, lenguaje oral) sino que también abarca el contexto y los usos y las funciones del lenguaje en situaciones reales. El libro Pragmatics: cognition, context, culture (Alba-Juez y Mackenzie, 2016) ofrece una clara introducción actual y bien fundamentada al estudio de la pragmática, ayudada por abundantes ejemplos y ejercicios de gran utilidad tanto para un aprendizaje autónomo como para su explotación en cursos de lingüística aplicada, traducción o didáctica de lenguas modernas.

El libro abre su primer capítulo con una reflexión acerca de la necesaria toma de conciencia de la dimensión pragmática que encierra todo fenómeno lingüístico y comunicativo. La pragmática nos permite comprender la comunicación teniendo en cuenta no solo los significados literales, sino también los significados indirectos, implícitos u ocultos. Para profundizar en esta cuestión, es necesario partir de un concepto dinámico del contexto lingüístico, social, sociocultural y cognitivo, así como del contexto "emocional" o "actitudinal" que afecta tanto a la transmisión como a la mediación y recepción del mensaje. Así pues, en este primer capítulo se repasan brevemente los principales acercamientos teóricos a la pragmática, con especial atención a dos que tradicionalmente se han identificado como dos vertientes distintas, pese a que ahora se están acercando cada vez más: el enfoque anglosajón (Levinson, Leech, Yule, Cummins), centrado en la "micropragmática", y el enfoque europeo o "macropragmática" (Verschueren), que adopta una perspectiva más amplia que acoge la acción comunicativa en cualquier tipo de contexto.

Los siguientes capítulos ofrecen una acertada visión de los siguientes temas: los actos de habla, la referencia y la inferencia, la cortesía y la descortesía y la relevancia. Destaca, en especial, el capítulo sobre la cortesía por su amplia y a la vez sintética revisión del complejo panorama de las teorías imperantes en esta área y por su fructífera comparación del trabajo de los investigadores de cortesía del ámbito anglosajón (Brown y Levinson, Culpeper) y del ámbito hispánico (Kaul de Marlangeon, Alba-Juez). Los autores del volumen abogan por situar la cortesía y la descortesía en un continuo que presenta una dimensión relacional, y aportan una 
taxonomía ampliada de los actos de habla que alberga desde los actos de agresión verbal hasta los actos valorizadores de la imagen positiva, como el halago. Quienes deseen ahondar en el estudio de la cortesía encontrarán en este capítulo una excelente base de referencia.

Muy sugerente resulta también el último capítulo, ya que presta atención a diferentes aspectos de la pragmática que siguen representando un reto para el investigador. En él se dedican varios apartados a las conexiones que la pragmática mantiene con la gramática y el léxico, y se explora el sugerente nexo existente entre la pragmática y la fonología, que puede incluso relacionarse con la sociolingüística y los estudios de identidad. Queda quizá menos clara la sección sobre la teoría de la valoración (Appraisal) y sus vínculos con la pragmática, tal vez porque la complejidad de dicha teoría no se presta a una breve revisión y porque sus relaciones con la pragmática se materializan en múltiples niveles. Por otra parte, las secciones sobre la pragmática histórica y la ciberpragmática destacan por su concisión y pertinencia.

En definitiva, este libro es una guía atractiva, actual y accesible que ofrece abundante material para todas aquellas personas que quieran estudiar o enseñar pragmática en niveles de grado o posgrado, así como en cursos de formación en lingüística aplicada. Además de proporcionar una visión global de las principales teorías, el volumen explora las múltiples conexiones entre la pragmática y otros ámbitos de la comunicación humana, ofreciendo así un punto de partida para indagar más en las interrelaciones entre lenguaje y comportamiento, forma y función, etc. Una de sus principales virtudes es su estilo práctico, con numerosos ejemplos actuales, caricaturas, dibujos y textos de muy diversa índole. Asimismo, cabría subrayar que al final de cada capítulo se incluye un resumen de los conceptos clave explicados y un cuestionario de quince preguntas de autoevaluación, seguido de varias actividades adicionales que tienen como objetivo promover la reflexión y profundización en diferentes aspectos de los contenidos del volumen. Todos estos materiales son, sin duda, de enorme utilidad para quienes empleen este libro de manera autónoma para iniciarse en el estudio de la pragmática.

Ruth Breeze

rbreeze@unav.es

Instituto Cultura y Sociedad, Universidad de Navarra 